\title{
Force XXI Training Program-Digital Project: Report on Development and Lessons Learned
}

\author{
Christopher R. Graves, David M. Pratt, and \\ Charlotte H. Campbell \\ Human Resources Research Organization \\ Johnny D. Allen and Kevin G. Thorson \\ Raytheon Systems Company \\ Samuel N. Jenkins \\ Litton PRC \\ Kathleen A. Quinkert \\ U.S. Army Research Institute
}

Armored Forces Research Unit

Barbara A. Black, Chief

U.S. Army Research Institute for the Behavioral and Social Sciences 5001 Eisenhower Avenue, Alexandria, Virginia 22333-5600

November 1999 